\title{
Visualizing the entire range of noncovalent interactions in nanocrystalline hybrid material using 3D electron diffraction
}

Yi Luo ${ }^{1, \dagger, *}$, Max T.B. Clabbers ${ }^{1, \dagger}$, Jian Qiao $^{2}$, Zhiqing Yuan ${ }^{2}$, Weimin Yang ${ }^{2, *}$, and Xiaodong Zou ${ }^{1, *}$ ${ }^{1}$ Department of Materials and Environmental Chemistry, Stockholm University, SE-106 91 Stockholm, Sweden.

${ }^{2}$ State Key Laboratory of Green Chemical Engineering and Industrial Catalysis, Sinopec Shanghai Research Institute of Petrochemical Technology, 1658 Pudong Beilu, Shanghai 201208, China.

${ }^{*}$ Correspondence authors: X.Z. (xzou@mmk.su.se), W.Y. (yangwm.sshy@sinopec.com), and Y.L. (yi.luo@mmk.su.se)

${ }^{\dagger}$ These authors contributed equally to this work.

\section{Abstract}

Noncovalent interactions are essential in the formation and function of a diverse range of hybrid materials. However, reliably identifying the noncovalent interactions in nanocrystalline materials remains challenging using conventional methods such as X-ray diffraction and spectroscopy. Here, we demonstrate that the entire range of noncovalent interactions in a nanocrystalline aluminophosphate hybrid material SCM-34 can be directly visualized by accurately determining all atomic positions using 3D electron diffraction (3D ED). The resolved hydrogen atoms reveal the protonation states of the inorganic and organic components. All the noncovalent hydrogen bonding, electrostatic, $\pi-\pi$ stacking, and Van der Waals interactions were unambiguously resolved, providing a detailed insight into the material formation mechanism. The data are sufficiently accurate to distinguish the different types of covalent bonds based on their bond lengths, and we observed an elongated terminal $\mathrm{P}=\mathrm{O} \pi$-bond caused by noncovalent interactions. Our results illustrate 3D ED can be a powerful tool for resolving detailed noncovalent interactions in nanocrystalline hybrid materials, improving our understanding of hybrid systems and guiding the development of novel functional materials.

\section{Introduction}

Noncovalent interactions are at the core of supramolecular chemistry and include electrostatic, hydrogen bonding, $\pi-\pi$ stacking, and Van der Waals interactions ${ }^{1-4}$. Although these noncovalent interactions are relativity weak compared to covalent bonding, they play a vital role in the formation and chemical processes of functional hybrid materials ${ }^{5}$. Many important functional materials such as catalysts ${ }^{6,7}$, adsorbents ${ }^{8-10}$, molecular machines $^{11,12}$, and pharmaceuticals ${ }^{13,14}$ have been developed relying on noncovalent interactions, as well as novel strategies for the development of advanced functional materials ${ }^{15-17}$. For example, zeolites and metalorganic frameworks are commonly synthesized through noncovalent interactions between the organic and inorganic components ${ }^{18,19}$. The flexibility and wide variety of noncovalent interactions between the organic structure-directing agents (e.g. amine and quaternary ammonium cation) and the inorganic components (e.g. aluminosilicate and aluminophosphate) makes these materials highly tuneable, enabling the development of 
many diverse zeolitic hybrids. ${ }^{17,18,20}$ Reliably identifying the entire range of noncovalent interactions involved in hybrid material formation is therefore crucial in the development of novel functional materials and supramolecular chemistry.

Spectroscopy techniques such as Nuclear magnetic resonance (NMR), Infrared, Ultraviolet-visible, and Raman are used to characterize noncovalent interactions ${ }^{21-23}$. These techniques are however limited by the specified signal channel, resolution, and signal/noise ratio of the spectra. The results can therefore be ambiguous and typically only partial noncovalent interactions can be resolved, even when combining different spectroscopy techniques.

Single crystal X-ray diffraction (SCXRD) is used to resolve the noncovalent interactions in crystalline hybrid materials by directly determining the atomic coordinates ${ }^{7,24,25}$, and enables distinguishing the influence of noncovalent interactions on the covalent bond lengths ${ }^{26}$. However, SCXRD requires relatively large $(>5 \times 5 \times 5$ $\mu \mathrm{m}^{3}$ ) and well-ordered crystalline samples. Growing large crystals devoid from any defects and disorders can be challenging and time-consuming, especially for samples that assemble via relatively weak noncovalent interactions. These factors can complicate or even prohibit structure determination of hybrid materials by SCXRD. Alternatively, powder X-ray diffraction (PXRD) can be used to gain structural insights from samples composed of small micron- or nanometer-sized crystals ${ }^{27}$. However, PXRD requires a highly isomorphous sample and the peak overlapping in the one-dimensional pattern can make structure determination difficult and highly involved. The noncovalent interactions resolved from the PXRD data are therefore often ambiguous owing to the large number of restraints that are required in structure refinement.

Electrons are scattered by the electrostatic potential of the atoms at the cost of significantly lower radiation damage compared to X-rays ${ }^{28}$, enabling the use of nanocrystalline samples of inorganic and organic materials for structure determination ${ }^{29}$. Electrons are more sensitive towards the lighter hydrogen atoms relative to Xrays, facilitating the localization of individual hydrogen atoms in organic and inorganic samples at sub-atomic resolution $^{30-35}$. Three-dimensional electron diffraction (3D ED) data are collected analogously to SCXRD using continuous sample rotation as demonstrated in MicroED ${ }^{36}$ and implemented in $\mathrm{CRED}^{37,38}$, or alternatively by combining stepwise rotation with precession or beam tilt ${ }^{37,39}$, or merging many still diffraction patterns in SerialED ${ }^{40}$. Recently, rapid structure determination of organic compounds from nanocrystals was demonstrated using continuous rotation data collection at time scales competitive with SCXRD $^{32,33}$. Furthermore, 3D ED data can be complemented by PXRD, NMR, and DFT to characterize and provide additional support for the proposed structural models and their supramolecular assemblies ${ }^{41-43}$. For example, 3D ED was used in combination with NMR to reveal the hydrogen bonding network in small molecule crystals ${ }^{41}$. Electron diffraction was used to determine the coordinates of the non-hydrogen atoms, whereas NMR was used to then assign the correct atom types, localize the hydrogen atoms, and derive the protonation state ${ }^{41}$. Noncovalent interactions involving hydrogen bonding and $\pi$-stacking forming the basis in heterochiral supramolecular polymerization could successfully be resolved using 3D ED data combined with DFT calculations ${ }^{43}$. 
Here, we exclusively use 3D ED to determine the structure of a nanocrystalline aluminophosphate hybrid material SCM-34, revealing the entire range of noncovalent interactions involved in material formation through resolving all atomic positions. The accurate atomic positions provide an insight into the hydrogen bonding, electrostatic, $\pi-\pi$ stacking, and Van der Waals interactions between the inorganic and organic components of the hybrid material, as well as the protonation state and the effect of noncovalent interactions on the bond length of the terminal $\mathrm{P}=\mathrm{O} \pi$-bond. We corroborate our results using $\mathrm{PXRD}$ and NMR to confirm the unit cell parameters, our proposed structural model, and the protonation state of the organic and inorganic components.

\section{Results}

Table 1. Data collection and structure refinement of SCM-34

\begin{tabular}{lc}
\hline \multicolumn{2}{c}{ Crystal data } \\
\hline Formula & $\left|\left(\mathrm{C}_{6} \mathrm{~N}_{3} \mathrm{H}_{13}\right)_{2}\right|\left[\mathrm{P}_{4} \mathrm{Al}_{2} \mathrm{O}_{18} \mathrm{H}_{6}\right]$ \\
Crystal system & Triclinic \\
Space group & $P-1$ \\
$a, b, c(\AA)$ & $6.831,8.418,12.068$ \\
$\alpha, \beta, \gamma\left({ }^{\circ}\right)$ & $100.78,101.60,91.33$ \\
$\mathrm{~V}\left(\AA^{3}\right)$ & 666.5 \\
\multicolumn{2}{c}{ Data details } \\
Temperature $(\mathrm{K})$ & 293 \\
Radiation $(\AA)$ & Electrons, 0.0251 \\
Number of merged data sets & 7 \\
$\mathrm{~d}_{\text {min }}, \mathrm{d}_{\text {max }}(\AA)$ & $0.75,11.80$ \\
Completeness $(\%)$ & 98.8 \\
Total, Unique reflection, Rint & $18143,3258,0.2507$ \\
Observed data $[I>2.0 \sigma(I)]$ & 2385 \\
\multicolumn{2}{c}{ Refinement } \\
$\mathrm{N}_{\text {reflections }}, \mathrm{N}_{\text {parameters }}, \mathrm{N}_{\text {restraints }}$ & $3258,214,2$ \\
$R 1, w R 2\left[F^{2}>2.0 \sigma\left(F^{2}\right)\right]$ & $0.1861,0.4468$ \\
$R 1, w R 2($ all data) & $0.2224,0.4743$ \\
\hline
\end{tabular}

We synthesized the hybrid material SCM-34 using 1-(3-aminopropyl)imidazole (API) as the structuredirecting agent under hydrothermal conditions (Figure S1, Supplementary Methods). The resulting crystals have a plate-like morphology with average dimensions of $3.0 \times 1.5 \times 0.2 \mu \mathrm{m}$ (Figure S2). 3D ED data were collected from nine crystals at room temperature during a 2-hour session on a transmission electron microscope (TEM) using the program Instamatic ${ }^{38}$. The data were processed using $X D S^{44}$, suggesting a triclinic unit cell (Table 1, S1 and S2, Figure S4). Seven datasets were selected for data merging based on their internal consistency, with an overall completeness of $98.8 \%$ up to $0.75 \AA$ resolution (Table 1 and S3).

The structure of SCM-34 was solved $a b$ initio using direct methods in SHELXT ${ }^{45}$ in space group $P-1$. All nonhydrogen atom $(\mathrm{P}, \mathrm{Al}, \mathrm{C}, \mathrm{N}$, and $\mathrm{O})$ positions were successfully resolved. During structure refinement using SHELXL ${ }^{46}, 14$ out of 16 symmetry independent hydrogen atoms were located directly based on the strong 
1 difference Fourier peaks (Figure 1 and S5). They were then constrained by ideal geometry, but allowing the $2 \mathrm{X}-\mathrm{H}(\mathrm{X}=\mathrm{C}, \mathrm{N}$, and $\mathrm{O})$ distances to refine. The exceptions being the $\mathrm{C} 2-\mathrm{H} 3$ and $\mathrm{C} 3-\mathrm{H} 4$ distances that were 3 restrained to the ideal hydrogen bond lengths from neutron diffraction of $1.08 \AA$ with a sigma of $0.02 \AA^{47}$. The 4 refined chemical composition is $\left|\left(\mathrm{C}_{6} \mathrm{~N}_{3} \mathrm{H}_{13}\right)_{2}\right|\left[\mathrm{P}_{4} \mathrm{Al}_{2} \mathrm{O}_{18} \mathrm{H}_{6}\right]$, and the refinement converged with $R 1=0.186$ and $5 \quad w R 2=0.447\left(\mathrm{~F}^{2}>2.0 \sigma\left(\mathrm{F}^{2}\right)\right.$, Table 1$)$.

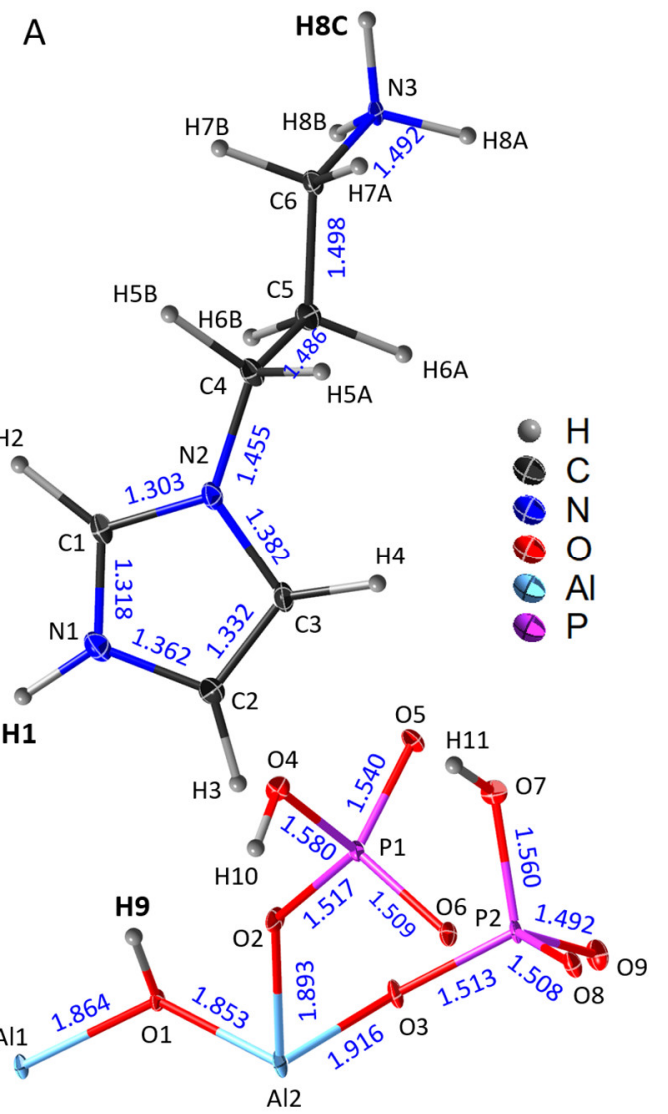

B
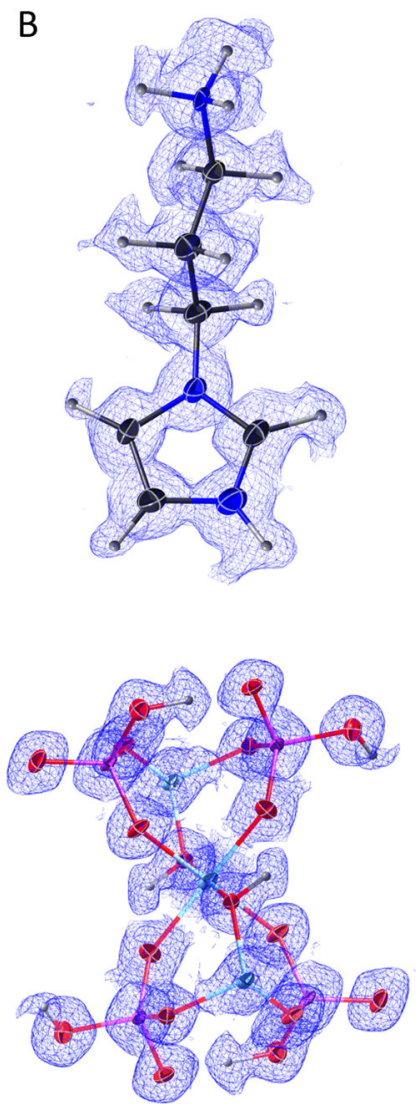

Figure 1. Structure of SCM-34 determined using 3D ED data. A) The connectivities of 37 atoms in the asymmetric unit of SCM-34 (10\% probability displacement ellipsoids). The protonation sites (H1, H8C, and H9, highlighted in bold) are identified in the organic API molecule and the inorganic aluminophosphate chain. Bond lengths between non-hydrogen atoms are indicated (in $\AA$, blue). B) Observed Fourier map for the API molecule and aluminophosphate chain (isosurface level: $1.35 \sigma$ ).

The SCM-34 structure consists of inorganic aluminophosphate chains interacting with the organic API molecules (Figure 2). The aluminophosphate chains are closely related to $\mathrm{Na}_{4} \mathrm{Al}\left(\mathrm{PO}_{4}\right)_{2}(\mathrm{OH})^{48}$ and $\mathrm{AlPO}-$ $\mathrm{CJ} 10^{49}$. The chains in SCM-34 are built of $\mathrm{AlO}_{4}(\mathrm{OH})_{2}$ octahedrons $\left(\mathrm{Al}^{3+}\right)$ and $\mathrm{O}=\mathrm{PO}_{2}(\mathrm{OH})$ tetrahedrons $\left(\mathrm{P}^{5+}\right)$, arranged along the crystallographic $a$ direction. The adjacent $\mathrm{AlO}_{4}(\mathrm{OH})_{2}$ octahedrons are connected via shearing the protonated $\mathrm{O} 1$ atoms (proton: $\mathrm{H} 9$ ), and are further bridged by the $\mathrm{O}=\mathrm{PO}_{2}(\mathrm{OH})$ tetrahedrons (Figure 1 and 2). Two protons (H1 and H8C) were identified in each API molecule, indicating that each API molecule was double-protonated during the synthesis (Figure 1). In the chains, the bond lengths of Al-O bonds in $\mathrm{Al}-\mathrm{O}-\mathrm{Al}$ and $\mathrm{Al}-\mathrm{O}-\mathrm{P}$ are 1.853(6) 1.864(4) $\AA$ and 1.885(7) 1.930(6) $\AA$, respectively (Table S4). While 
1 the bond lengths between $\mathrm{P}$ and $\mathrm{O}$ in $\mathrm{P}-\mathrm{O}-\mathrm{H}, \mathrm{P}-\mathrm{O}-\mathrm{Al}$, and $\mathrm{P}=\mathrm{O}$ are 1.560(9) 1.580(8) $\AA, 1.508(7) \sim 1.517(6)$

$2 \AA$, and 1.492(8) 1.540(7) $\AA$, respectively (Table S4). In the API molecule, the $\mathrm{C}-\mathrm{N}$ bond lengths in the 3 imidazole ring and tail are 1.318(14) 1.382(15) $\AA$ and 1.455(12) 1.492(10) $\AA$, respectively (Table S5). The 4 C-C bond length in the imidazole ring is 1.332(13) and shorter than the ones in the chain tail 5 (1.486(13) 1.498(13) ^).
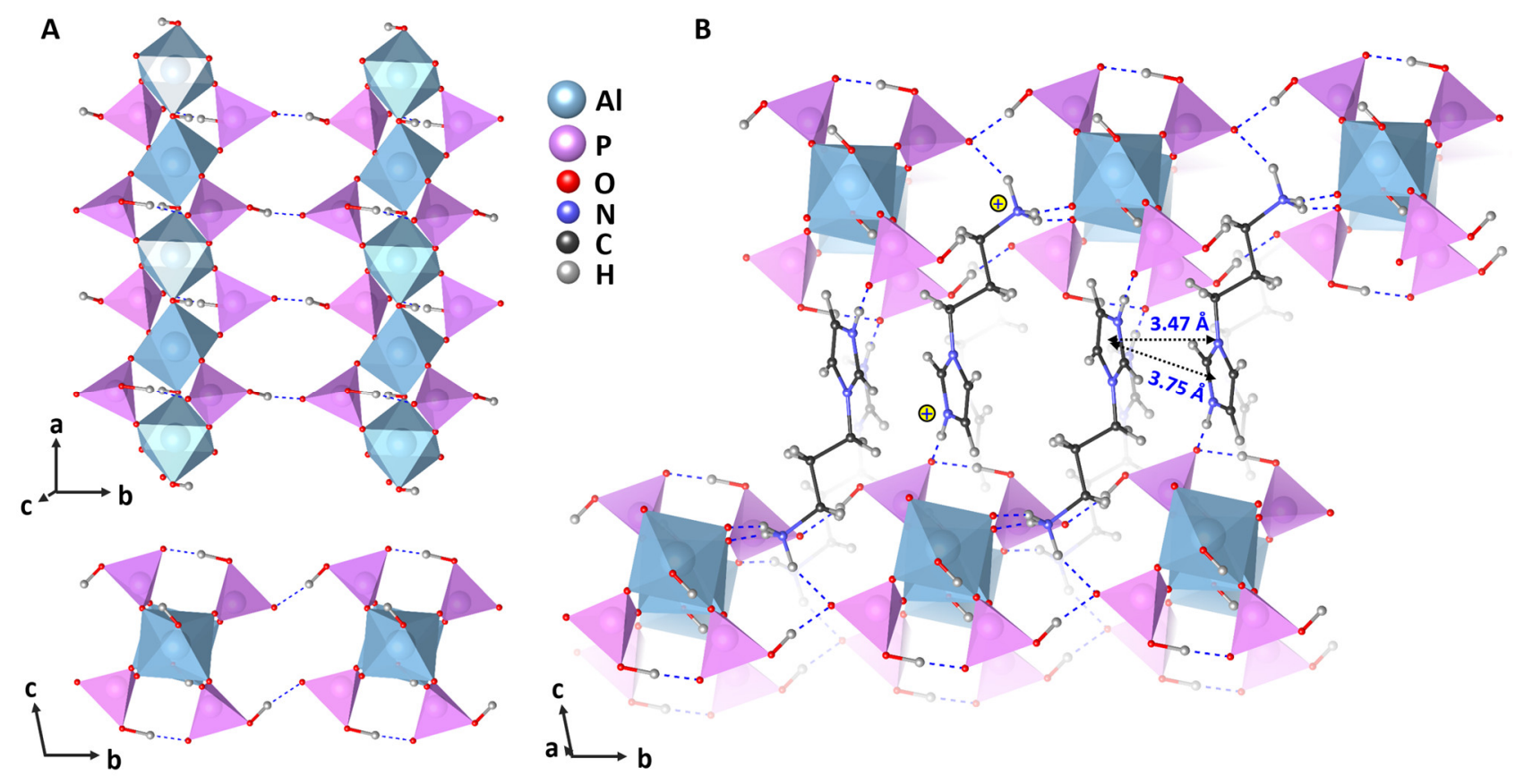

Figure 2. Structural analysis of the resolved hydrogen bonding, electrostatic, and $\pi-\pi$ stacking interactions for SCM-34. A) Aluminophosphate chains are built from $\mathrm{AlO}_{4}(\mathrm{OH})_{2}$ octahedrons and $\mathrm{O}=\mathrm{PO}_{2}(\mathrm{OH})$ tetrahedrons. The negatively charged chains are stabilized and aligned together via the hydrogen bonding interactions (blue dotted line) inside and between the chains. B) Location of the API molecules and their noncovalent interactions. Each API molecule is double-protonated. The protonated parts $\left(-\left(\mathrm{NH}_{3}\right)^{+},-(\mathrm{NH})^{+}-\right)$are approaching the negatively charged aluminophosphate chains, and binding the chains along the $b$ and $c$ directions through the hydrogen bonding and electrostatic interactions. Two API molecules are packed as a dimer through $\pi-\pi$ stacking interactions of imidazole rings to further stabilize the hybrid structure along the $b$ direction.

The hybrid structure of SCM-34 is assembled from the aluminophosphate chains and API molecules through different types of noncovalent interactions (Figure 2). In the aluminophosphate chains, the neighboring $\mathrm{O}=\mathrm{PO}_{2}(\mathrm{OH})$ tetrahedrons interact via forming hydrogen bonds between their terminal $\mathrm{P}-\mathrm{OH}$ and $\mathrm{O}=\mathrm{P}$ groups. The distance between the donor (D) and acceptor (A) atoms ( $\mathrm{P}-\mathrm{O} 7-\mathrm{H} 11 \cdots \mathrm{O} 5=\mathrm{P})$ is 2.554(10) $\AA$, indicating a strong interaction is formed to stabilize the chains. Meanwhile, the aluminophosphate chains are further aligned via strong hydrogen bonding interactions $(\mathrm{P}-\mathrm{O} 4-\mathrm{H} 10 \cdots 0 \mathrm{O}=\mathrm{P})$ between their neighboring parallel chains (Figure 2A, Table 2). The summed composition of the chains $\left(\left[\mathrm{P}_{4} \mathrm{Al}_{2} \mathrm{O}_{18} \mathrm{H}_{6}\right]^{4-}\right)$ within a single unit cell has a negative charge of -4 , which is balanced by the positive charge from the two double-protonated API molecules $\left(\left|\left(\mathrm{C}_{6} \mathrm{~N}_{3} \mathrm{H}_{13}\right)_{2}\right|^{4+}\right)$. The protonated parts $\left(-\left(\mathrm{NH}_{3}\right)^{+},-(\mathrm{NH})^{+}-\right)$of the API molecules are approaching the 
negatively charged chains, and binding the chains along the $b$ and $c$ directions through hydrogen bonding and electrostatic interactions (Figure 2B). All hydrogen bonds are chemically reasonable, and their strengths were deduced from the distances of $\mathrm{H} \cdots A$ and $\mathrm{D} \cdots A$, and the angles of $\mathrm{D}-\mathrm{H} \cdots \cdot \mathrm{A}(\text { Table } 2 \text { and Figure } 2)^{50,51}$. The $\left(\mathrm{NH}_{3}\right)^{+}$part places three moderate hydrogen bonds (N3-H8A $\cdots$ O 8, N3-H8B $\cdots$ O9, and N3-H8A $\cdots$ O3) to the aluminophosphate chain. While the $-(\mathrm{NH})^{+}-$part gives rise to a strong hydrogen bond $(\mathrm{N} 1-\mathrm{H} 1 \cdots \mathrm{O} 5)$. Meanwhile, API molecules are observed to be packed as dimers via the imidazole rings with the shortest distance of $3.47 \AA$ and central distance of $3.75 \AA$, indicating the formation of offset type $\pi-\pi$ stacking interactions $^{52}$. The offset type $\pi-\pi$ stacking interactions between the imidazole rings further stabilize the structure along the $b$ direction. In addition, the van der Waals interactions are illustrated by the Hirshfeld surface for the structure. The contact distsances that about the sum of the van der Waals radii are colored white on the surface (Figure 3).

Table 2. Hydrogen bonding interactions in SCM-34.

\begin{tabular}{lllllll}
\hline $\begin{array}{l}\text { Donor-H} \cdots \\
\text { Acceptor }\end{array}$ & $\mathrm{D}-\mathrm{H}(\AA)$ & $\mathrm{H} \cdots \cdot \mathrm{A}(\AA)$ & $\mathrm{D} \cdots \mathrm{A}(\AA)$ & $\mathrm{D}-\mathrm{H} \cdots \cdot \mathrm{A}\left({ }^{\circ}\right)$ & $\begin{array}{l}\text { Interaction } \\
\text { strength }\end{array}$ & $\begin{array}{l}\text { Details of the } \\
\text { acceptor groups }\end{array}$ \\
\hline $\mathrm{N} 1-\mathrm{H} 1 \cdots \mathrm{O} 5$ & $1.01(5)$ & $1.57(5)$ & $2.586(10)$ & $167(5)$ & strong & $\mathrm{P}=\mathrm{O}$ terminal O \\
$\mathrm{N} 3-\mathrm{H} 8 \mathrm{\cdots} \cdots \mathrm{O} 8$ & $1.04(4)$ & $1.79(4)$ & $2.806(9)$ & $164(3)$ & moderate & $\mathrm{P}-\mathrm{O}-\mathrm{A} 1$ bridge $\mathrm{O}$ \\
$\mathrm{N} 3-\mathrm{H} 8 \mathrm{~B} \cdots \mathrm{O} 9$ & $1.04(4)$ & $1.72(4)$ & $2.688(12)$ & $151.5(11)$ & moderate & $\mathrm{P}=\mathrm{O}$ terminal O \\
$\mathrm{N} 3-\mathrm{H} 8 \mathrm{C} \cdots \mathrm{O} 3$ & $1.04(4)$ & $1.77(4)$ & $2.781(8)$ & $162(2)$ & moderate & $\mathrm{P}-\mathrm{O}-\mathrm{A} 1$ bridge $\mathrm{O}$ \\
$\mathrm{O} 4-\mathrm{H} 10 \cdots \mathrm{O} 9$ & $0.97(5)$ & $1.56(5)$ & $2.505(9)$ & $165(5)$ & strong & $\mathrm{P}=\mathrm{O}$ terminal O \\
$\mathrm{O} 7-\mathrm{H} 11 \cdots \mathrm{O} 5$ & $1.08(6)$ & $1.48(6)$ & $2.554(10)$ & $171(5)$ & strong & $\mathrm{P}=\mathrm{O}$ terminal O \\
\hline
\end{tabular}

To corroborate our results, we performed additional characterization only used for structure validation. The unit cell dimensions derived from the PXRD data are in good agreement with those determined from our 3D ED data (Table 1, S2, Figure S1). The maximum deviations of the unit cell lengths and angles are $0.22 \AA$ and $0.14^{\circ}$, respectively. The structural model of SCM-34 was validated using ${ }^{31} \mathrm{P},{ }^{27} \mathrm{Al}$, and ${ }^{13} \mathrm{C} \mathrm{NMR} \mathrm{spectroscopy}$, inductively coupled plasma (ICP), and chemical element analysis. The ${ }^{31} \mathrm{P}$ and ${ }^{27} \mathrm{Al}$ NMR spectra indicate that $\mathrm{P}$ and $\mathrm{Al}$ are four and six-coordinated, respectively (Figure S6). The ${ }^{13} \mathrm{C}$ NMR spectrum shows the API molecules are accommodated in the structure and could be double-protonated (Figure S7). The calculated molar ratios of $\mathrm{P} / \mathrm{Al}$ and $\mathrm{C} / \mathrm{N}$ in SCM-34 are 2.1 and 2.0, respectively, which is consistent with their molar ratios in the chemical composition $\left(\left|\left(\mathrm{C}_{6} \mathrm{~N}_{3} \mathrm{H}_{13}\right)_{2}\right|\left[\mathrm{P}_{4} \mathrm{Al}_{2} \mathrm{O}_{18} \mathrm{H}_{6}\right]\right)$ resolved from the $3 \mathrm{D}$ ED data. ${ }^{1} \mathrm{H}$ solid-state NMR and FT-IR spectroscopies were applied to detect the protonation state of the API molecules and aluminophosphate chains. The ${ }^{1} \mathrm{H}$ solid-state NMR spectrum shows a broad peak centered at $6.78 \mathrm{ppm}$ and a sharp peak at $0.86 \mathrm{ppm}$ (Figure S8). The sharp peak at $0.86 \mathrm{ppm}$ was assigned to $\mathrm{Al}-\mathrm{OH}$ or $\mathrm{P}-\mathrm{OH}$ groups ${ }^{54}$, the broad peak (6.78 ppm) however could not offer any information regarding the protonation state of the API molecules. In the FT-IR spectrum, the signal attributed to $\mathrm{Al}-\mathrm{OH}$ and $\mathrm{P}-\mathrm{OH}$ groups are overlapping at 3657 $\mathrm{cm}^{-1}$ and the signal of different $\mathrm{C}-\mathrm{H}$ and $\mathrm{N}-\mathrm{H}$ groups is overlapping in the region of $2750-3200 \mathrm{~cm}^{-1}$ (Figure S9) ${ }^{55}$. The signal overlapping in the ${ }^{1} \mathrm{H}$ solid-state NMR and FT-IR spectrum makes it challenging to reliably 
1 interpret the protonation state of the API molecules and the aluminophosphate chains without accurate

2 knowledge of the structure.
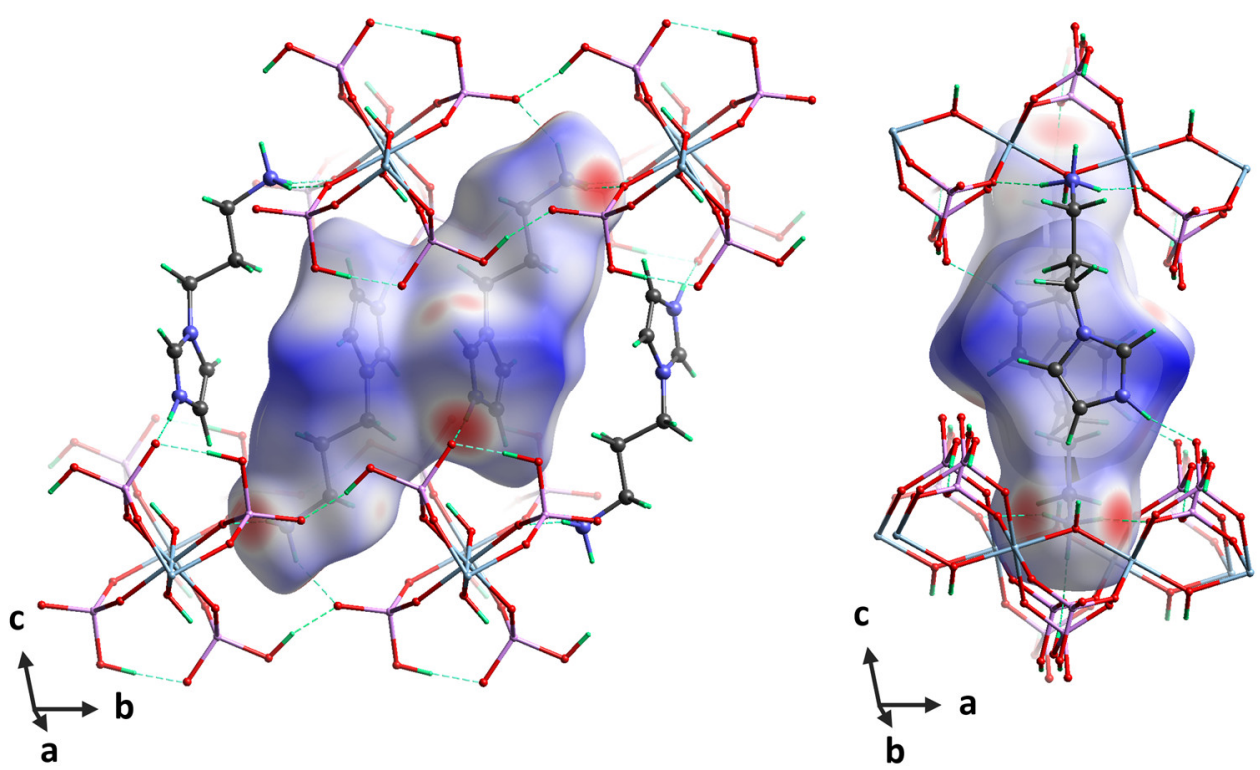

Figure 3. Hirshfeld surface for the API molecules (mapped with $d_{n o r m}$ over the range $-0.806 \sim 1.932$ ) in SCM-34. The color scheme used on this surface indicates the contact distance to the aluminophosphate chains: contacts that are shorter than the sum of the van der Waals radii are colored red, contacts about equal to the sum of the van der Waals radii are colored white, blue represents the longer contacts ${ }^{53}$.

\section{Discussion and conclusions}

We present the structure of the nanocrystalline hybrid material SCM-34. All atomic positions were resolved from our 3D ED data, even including the hydrogen atoms (Figure 1). The $\mathrm{X}-\mathrm{H}(\mathrm{X}=\mathrm{C}, \mathrm{N}, \mathrm{O})$ hydrogen bond lengths, except those of $\mathrm{C} 2-\mathrm{H} 3$ and $\mathrm{C} 3-\mathrm{H} 4$, were refined without restraints and are on average longer than the idealized hydrogen bond lengths from X-ray diffraction (averaged deviation: $0.164 \AA$, Table S6) ${ }^{47}$. This is in line with previous observations that showed the hydrogen bond lengths observed in electron diffraction are closer to the inter-nuclei distances observed with neutron diffraction ${ }^{34,56}$. The bond lengths of $\mathrm{C} 2-\mathrm{H} 3$ and C3$\mathrm{H} 4$ had to be restrained as the positions of $\mathrm{H} 3$ and $\mathrm{H} 4$ atoms were not well resolved in our electrostatic potential map (Figure 1 and S5). This may be because H3 and H4 are located on a region of the API molecule that has higher structural flexibility, and due to the fact that the two hydrogen atoms likely are more discorded as they are pointing outwards to the empty pockets between the chains (Figure 2). The hydrogen atoms involved in noncovalent hydrogen-bonding interactions between the aluminophosphate chains and API molecules were unambiguously identified from the difference peaks in our map (Figure S5). The protons H1, H8C, and H9 in the structure indicate that the aluminophosphate chains and the API molecules were protonated during the synthesis.

The covalent bond lengths between the non-hydrogen atoms in our structure are accurate with an average deviation of $0.013 \AA$ compared to the reported SCXRD bond lengths, enabling the assignment of each bonding 
type (Table S4 and S5). In the API molecules, the bond lengths of N1-C1, N1-C2, N2-C4, N3-C6, C2-C3, and $\mathrm{C} 5-\mathrm{C} 6$ are almost identical to their corresponding reported SCXRD bond lengths ( $0.003 \AA$ deviation). The $\mathrm{C}-\mathrm{N}$ and $\mathrm{C}-\mathrm{C}$ bonds in the imidazole ring and tail of the API molecule can be distinguished based on their bond lengths (Table S5). In the aluminophosphate chains, based on the observed bond lengths, we can

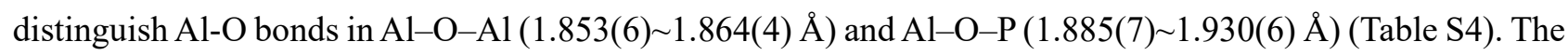
different bond lengths between $\mathrm{P}$ and $\mathrm{O}$ in $\mathrm{P}-\mathrm{O}-\mathrm{H}, \mathrm{P}-\mathrm{O}-\mathrm{Al}$, and $\mathrm{P}=\mathrm{O}$ can be identified from our data, with the exception of the $\mathrm{P} 1=\mathrm{O} 5$ terminal bond length (1.540(7) $\AA$, Table S4). Notably, the bond length of $\mathrm{P} 1=\mathrm{O} 5$ $(1.540(7) \AA)$ is elongated when compared to the expected bond length $(1.500 \AA)$ and the P2=O9 (1.492(8) $\AA)$ bond length. This elongation may be the result of strong hydrogen bonding and electrostatic interactions with this oxygen $\left(\mathrm{P} 1=\mathrm{O} 5 \cdots \cdot \mathrm{H} 11-\mathrm{O}\right.$ and $\left.\mathrm{P}=\mathrm{O} 5 \cdots \cdot \mathrm{H} 1-\mathrm{N} 1^{+}\right)$. Systematic studies have shown the influence of strong hydrogen interactions on the lengthening of terminal $\mathrm{C}=\mathrm{O}$ bonds ${ }^{26}$. The electron of the $\mathrm{P} 1=\mathrm{O} 5 \pi$-bond can be delocalized by the interaction of hydrogen bonding, and the formal charge of the $\mathrm{O} 5$ atom accordingly becomes $-1^{57,58}$. The strong electrostatic interactions between $\mathrm{O} 5$ and $\mathrm{N} 1^{+}$therefore may contribute to elongation of the terminal bond $\mathrm{P} 1=\mathrm{O} 5$. The shorter bond length of $\mathrm{P} 2=\mathrm{O} 9$ may be the result of weaker hydrogen bonding and electrostatic interactions (Table 2 and Figure S10).

The hydrogen bond interactions were resolved based on the identified positions of the hydrogen, donor, and acceptor atoms in the structure. The strength of each interaction was interpreted based on the distances of $\mathrm{H} \cdots \mathrm{A}$ and D $\cdots \mathrm{A}$, and the angles of D-H$\cdots$ A (Table 2) ${ }^{59}$. The determined protons (H1, H8C, and H9) demonstrate the electrostatic interactions between the positively charged API molecules and the negatively charged aluminophosphate chains. The API molecules are packed as dimers via offset type $\pi-\pi$ stacking interactions between the imidazole rings. Furthermore, Van der Waals interactions between the chains and API molecules can be visualized from the Hirshfeld surface ${ }^{53}$. These noncovalent interactions can be calculated based on the accurate structural model, which enables the quantitative analysis of noncovalent interactions ${ }^{60}$. Identifying the entire range of noncovalent interactions in SCM-34 enables us to deduce the formation mechanism of this organic and inorganic hybrid material. Each aluminophosphate chain is built of $\mathrm{AlO}_{4}(\mathrm{OH})_{2}$ octahedrons and $\mathrm{O}=\mathrm{PO}_{2}(\mathrm{OH})$ tetrahedrons that are stabilized via hydrogen bonding interactions inside the chain. The formed chains are further aligned with the hydrogen bonding interactions between their neighboring parallel chains. To extend the structure into three dimensions along the $b$ and $c$ directions, API molecules are double-protonated and packed as dimers via $\pi-\pi$ stacking interactions to place the hydrogen bonding and electrostatic interactions with the parallel aligned aluminophosphate chains and build the organic-inorganic hybrid system. Van der Waals interactions play a role in shaping and supporting the hybrid structure.

The structure of the aluminophosphate chain in SCM-34 is similar to those reported previously in hybrid aluminophosphate materials, which were all determined by SCXRD from much larger crystals. ${ }^{48,49,61,62}$ Being able to determine the detailed structures of nanocrystalline materials, 3D ED can complement SCXRD and reveal the entire range of noncovalent interactions. We anticipate 3D ED may provide novel insights into the 
1 formation mechanism of hybrid materials, improving our understanding of supramolecular chemistry in

2 polycrystalline materials and facilitating the development of novel functional materials.

\section{Acknowledgements}

The authors acknowledge financial supports from the Swedish Research Council (VR, 2017-04321, 201900815), the Knut and Alice Wallenberg Foundation (KAW, 2016.0072, 2018.0237), the National Key R\&D Program of China (2017YFB0702800), and China Petrochemical Corporation (Sinopec Group).

\section{Author contributions}

Y.L., W.Y. and X.Z. designed the project. Y.L. and M.C. conducted the structure determination and refinement using 3D ED data, and data analysis of other general characterizations. J.Q. and Z.Q.Y. performed the synthesis of SCM-34 and conducted the general validation (NMR, XRD, TGA, et.al.). Y.L. and M.C. wrote the initial draft. All authors reviewed and commented on the manuscript.

\section{Notes}

The authors declare no competing financial interest.

\section{References}

(1) Cram, D. J.; Cram, J. M. Host-Guest Chemistry: Complexes between Organic Compounds Simulate the Substrate Selectivity of Enzymes. Science 1974, 183 (4127), 803-809.

(2) MacGillivray, L. R.; Atwood, J. L. A Chiral Spherical Molecular Assembly Held Together by 60 Hydrogen Bonds. Nature 1997, 389 (6650), 469-472.

(3) Atwood, J. L.; Barbour, L. J.; Jerga, A. Storage of Methane and Freon by Interstitial van Der Waals Confinement. Science 2002, 296 (5577), 2367-2369.

(4) Lee, D.-W.; Park, K. M.; Banerjee, M.; Ha, S. H.; Lee, T.; Suh, K.; Paul, S.; Jung, H.; Kim, J.; Selvapalam, N.; Ryu, S. H.; Kim, K. Supramolecular Fishing for Plasma Membrane Proteins Using an Ultrastable Synthetic HostGuest Binding Pair. Nature Chemistry 2011, 3 (2), 154-159.

(5) Steed, J. W.; Turner D. R.; Wallace, K. Core Concepts in Supramolecular Chemistry and Nanochemistry, John Wiley \& Sons 2007.

(6) Neel, A. J.; Hilton, M. J.; Sigman, M. S.; Toste, F. D. Exploiting Non-Covalent $\pi$ Interactions for Catalyst Design. Nature 2017, 543 (7647), 637-646.

(7) Takezawa, H.; Shitozawa, K.; Fujita, M. Enhanced Reactivity of Twisted Amides inside a Molecular Cage. Nature Chemistry 2020, 12 (6), 574-578.

(8) Lin, J. Y. S. Molecular Sieves for Gas Separation. Science 2016, 353 (6295), 121-122. 
(9) Katsoulidis, A. P.; Antypov, D.; Whitehead, G. F. S.; Carrington, E. J.; Adams, D. J.; Berry, N. G.; Darling, G. R.; Dyer, M. S.; Rosseinsky, M. J. Chemical Control of Structure and Guest Uptake by a Conformationally Mobile Porous Material. Nature 2019, 565 (7738), 213-217.

(10) Chai, Y.; Han, X.; Li, W.; Liu, S.; Yao, S.; Wang, C.; Shi, W.; da-Silva, I.; Manuel, P.; Cheng, Y.; Daemen, L. D.; Ramirez-Cuesta, A. J.; Tang, C. C.; Jiang, L.; Yang, S.; Guan, N.; Li, L. Control of Zeolite Pore Interior for Chemoselective Alkyne/Olefin Separations. Science 2020, 368 (6494), 1002-1006.

(11) Weissbuch, I.; Addadi, L.; Leiserowitz, L. Molecular Recognition at Crystal Interfaces. Science 1991, 253 (5020), 637-645.

(12) Muraoka, T.; Kinbara, K.; Aida, T. Mechanical Twisting of a Guest by a Photoresponsive Host. Nature 2006, 440 (7083), 512-515.

(13) Ma, X.; Zhao, Y. Biomedical Applications of Supramolecular Systems Based on Host-Guest Interactions. Chem. Rev. 2015, 115 (15), 7794-7839.

(14) Clabbers, M. T. B.; Fisher, S. Z.; Coinçon, M.; Zou, X.; Xu, H. Visualizing Drug Binding Interactions Using Microcrystal Electron Diffraction. Communications Biology 2020, 3 (1), 1-8.

(15) Qu, D.-H.; Wang, Q.-C.; Zhang, Q.-W.; Ma, X.; Tian, H. Photoresponsive Host-Guest Functional Systems. Chem. Rev. 2015, 115 (15), 7543-7588.

(16) Huang, R.-W.; Wei, Y.-S.; Dong, X.-Y.; Wu, X.-H.; Du, C.-X.; Zang, S.-Q.; Mak, T. C. W. Hypersensitive DualFunction Luminescence Switching of a Silver-Chalcogenolate Cluster-Based Metal-Organic Framework. Nature Chemistry 2017, 9 (7), 689-697.

(17) Corma, A.; Rey, F.; Rius, J.; Sabater, M. J.; Valencia, S. Supramolecular Self-Assembled Molecules as Organic Directing Agent for Synthesis of Zeolites. Nature 2004, 431 (7006), 287-290.

(18) Li, J.; Corma, A.; Yu, J. Synthesis of New Zeolite Structures. Chem. Soc. Rev. 2015, 44 (20), $7112-7127$.

(19) Stock, N.; Biswas, S. Synthesis of Metal-Organic Frameworks (MOFs): Routes to Various MOF Topologies, Morphologies, and Composites. Chem. Rev. 2012, 112 (2), 933-969.

(20) Lewis, D. W.; Willock, D. J.; Catlow, C. R. A.; Thomas, J. M.; Hutchings, G. J. De Novo Design of StructureDirecting Agents for the Synthesis of Microporous Solids. Nature 1996, 382 (6592), 604-606.

(21) Haldrup, K.; Vankó, G.; Gawelda, W.; Galler, A.; Doumy, G.; March, A. M.; Kanter, E. P.; Bordage, A.; Dohn, A.; van Driel, T. B.; Kjær, K. S.; Lemke, H. T.; Canton, S. E.; Uhlig, J.; Sundström, V.; Young, L.; Southworth, S. H.; Nielsen, M. M.; Bressler, C. Guest-Host Interactions Investigated by Time-Resolved X-Ray Spectroscopies and Scattering at MHz Rates: Solvation Dynamics and Photoinduced Spin Transition in Aqueous Fe(Bipy) ${ }_{3}^{2+} . J$. Phys. Chem. A 2012, 116 (40), 9878-9887.

(22) Hu, J.; Xu, T.; Cheng, Y. NMR Insights into Dendrimer-Based Host-Guest Systems. Chem. Rev. 2012, 112 (7), 3856-3891.

(23) Teyssandier, J.; Feyter, S. D.; Mali, K. S. Host-Guest Chemistry in Two-Dimensional Supramolecular Networks. Chem. Commun. 2016, 52 (77), 11465-11487. 
(24) Dalgarno, S. J.; Tucker, S. A.; Bassil, D. B.; Atwood, J. L. Fluorescent Guest Molecules Report Ordered Inner Phase of Host Capsules in Solution. Science 2005, 309 (5743), 2037-2039.

(25) Inokuma, Y.; Yoshioka, S.; Ariyoshi, J.; Arai, T.; Hitora, Y.; Takada, K.; Matsunaga, S.; Rissanen, K.; Fujita, M. X-Ray Analysis on the Nanogram to Microgram Scale Using Porous Complexes. Nature 2013, 495 (7442), 461466.

(26) Ichikawa, M. The Effect of Hydrogen Bonding on the Bond Lengths and Angles in the Carboxyl Group. Journal of Crystal and Molecular Structure 1979, 9 (2), 87-105.

(27) Baerlocher, C.; Gramm, F.; Massüger, L.; McCusker, L. B.; He, Z.; Hovmöller, S.; Zou, X. Structure of the Polycrystalline Zeolite Catalyst IM-5 Solved by Enhanced Charge Flipping. Science 2007, 315 (5815), 1113-1116.

(28) Henderson, R. The Potential and Limitations of Neutrons, Electrons and X-Rays for Atomic Resolution Microscopy of Unstained Biological Molecules. Quarterly Reviews of Biophysics 1995, 28 (2), 171-193.

(29) Dorset, D. L. Structural Electron Crystallography; Springer, 1995.

(30) Rodriguez, J. A.; Ivanova, M. I.; Sawaya, M. R.; Cascio, D.; Reyes, F. E.; Shi, D.; Sangwan, S.; Guenther, E. L.; Johnson, L. M.; Zhang, M.; Jiang, L.; Arbing, M. A.; Nannenga, B. L.; Hattne, J.; Whitelegge, J.; Brewster, A. S.; Messerschmidt, M.; Boutet, S.; Sauter, N. K.; Gonen, T.; Eisenberg, D. S. Structure of the Toxic Core of $\alpha-$ Synuclein from Invisible Crystals. Nature 2015, 525 (7570), 486-490.

(31) Palatinus, L.; Brázda, P.; Boullay, P.; Perez, O.; Klementová, M.; Petit, S.; Eigner, V.; Zaarour, M.; Mintova, S. Hydrogen Positions in Single Nanocrystals Revealed by Electron Diffraction. Science 2017, 355 (6321), 166-169.

(32) Gruene, T.; Wennmacher, J. T. C.; Zaubitzer, C.; Holstein, J. J.; Heidler, J.; Fecteau-Lefebvre, A.; Carlo, S. D.; Müller, E.; Goldie, K. N.; Regeni, I.; Li, T.; Santiso-Quinones, G.; Steinfeld, G.; Handschin, S.; Genderen, E.; Bokhoven, J. A.; Clever, G. H.; Pantelic, R. Rapid Structure Determination of Microcrystalline Molecular Compounds Using Electron Diffraction. Angew. Chem. Int. Ed. 2018, 57 (50), 16313-16317.

(33) Jones, C. G.; Martynowycz, M. W.; Hattne, J.; Fulton, T. J.; Stoltz, B. M.; Rodriguez, J. A.; Nelson, H. M.; Gonen, T. The CryoEM Method MicroED as a Powerful Tool for Small Molecule Structure Determination. ACS Cent. Sci. 2018, 4 (11), 1587-1592.

(34) Clabbers, M. T. B.; Gruene, T.; van Genderen, E.; Abrahams, J. P. Reducing Dynamical Electron Scattering Reveals Hydrogen Atoms. Acta Cryst A 2019, 75 (1), 82-93.

(35) Sawaya, M. R.; Rodriguez, J.; Cascio, D.; Collazo, M. J.; Shi, D.; Reyes, F. E.; Hattne, J.; Gonen, T.; Eisenberg, D. S. Ab Initio Structure Determination from Prion Nanocrystals at Atomic Resolution by MicroED. PNAS 2016, 113 (40), 11232-11236.

(36) Nannenga, B. L.; Shi, D.; Leslie, A. G. W.; Gonen, T. High-Resolution Structure Determination by ContinuousRotation Data Collection in MicroED. Nature Methods 2014, 11 (9), 927-930.

(37) Zhang, D.; Oleynikov, P.; Hovmöller, S.; Zou, X. Collecting 3D Electron Diffraction Data by the Rotation Method. Z. Kristallogr. 2010, 225 (2-3), 94-102.

(38) Cichocka, M. O.; Ångström, J.; Wang, B.; Zou, X.; Smeets, S. High-Throughput Continuous Rotation Electron Diffraction Data Acquisition via Software Automation. J. Appl. Cryst. 2018, 51 (6), 1652-1661. 
(39) Kolb, U.; Gorelik, T.; Kübel, C.; Otten, M. T.; Hubert, D. Towards Automated Diffraction Tomography: Part I-Data Acquisition. Ultramicroscopy 2007, 107 (6), 507-513.

(40) Smeets, S.; Zou, X.; Wan, W. Serial Electron Crystallography for Structure Determination and Phase Analysis of Nanocrystalline Materials. J. Appl. Cryst. 2018, 51 (Pt 5), 1262-1273.

(41) Guzmán-Afonso, C.; Hong, Y.; Colaux, H.; Iijima, H.; Saitow, A.; Fukumura, T.; Aoyama, Y.; Motoki, S.; Oikawa, T.; Yamazaki, T.; Yonekura, K.; Nishiyama, Y. Understanding Hydrogen-Bonding Structures of Molecular Crystals via Electron and NMR Nanocrystallography. Nature Communications 2019, 10 (1), 3537.

(42) Kim, L. J.; Xue, M.; Li, X.; Xu, Z.; Paulson, E.; Mercado, B.; Nelson, H. M.; Herzon, S. B. Structure Revision of the Lomaiviticins. J. Am. Chem. Soc. 2021, 143 (17), 6578-6585.

(43) Ueda, M.; Aoki, T.; Akiyama, T.; Nakamuro, T.; Yamashita, K.; Yanagisawa, H.; Nureki, O.; Kikkawa, M.; Nakamura, E.; Aida, T.; Itoh, Y. Alternating Heterochiral Supramolecular Copolymerization. J. Am. Chem. Soc. 2021, 143 (13), 5121-5126.

(44) Kabsch, W. XDS. Acta Cryst. D, 2010, 66 (2), 125-132.

(45) Sheldrick, G. M. SHELXT - Integrated Space-Group and Crystal-Structure Determination. Acta Cryst. A 2015, $71(1), 3-8$.

(46) Sheldrick, G. M. Crystal Structure Refinement with SHELXL. Acta Cryst. C 2015, 71 (1), 3-8.

(47) Gruene, T.; Hahn, H. W.; Luebben, A. V.; Meilleur, F.; Sheldrick, G. M. Refinement of Macromolecular Structures against Neutron Data with SHELXL2013. J. Appl. Cryst. 2014, 47 (1), 462-466.

(48) Attfield, M. P.; Morris, R. E.; Burshtein, I.; Campana, C. F.; Cheetham, A. K. The Synthesis and Characterization of a One-Dimensional Aluminophosphate: $\mathrm{Na}_{4} \mathrm{Al}_{1}\left(\mathrm{PO}_{4}\right)_{2}(\mathrm{OH})$. Journal of Solid State Chemistry 1995, $118(2), 412-416$.

(49) Yan, W.; Yu, J.; Shi, Z.; Wang, Y.; Zou, Y.; Xu, R. Synthesis and Characterization of a New Fluoroaluminophosphate Chain. Journal of Solid State Chemistry 2001, 161 (2), 259-265.

(50) Dannenberg, J. J. An Introduction to Hydrogen Bonding By George A. Jeffrey (University of Pittsburgh). Oxford University Press: New York and Oxford. 1997.

(51) Steiner, T. The Hydrogen Bond in the Solid State. Angew. Chem. Int. Ed. 2002, 41 (1), 48-76.

(52) Rashkin, M. J.; Waters, M. L. Unexpected Substituent Effects in Offset $\pi-\pi$ Stacked Interactions in Water. $J$. Am. Chem. Soc. 2002, 124 (9), 1860-1861.

(53) Spackman, P. R.; Turner, M. J.; McKinnon, J. J.; Wolff, S. K.; Grimwood, D. J.; Jayatilaka, D.; Spackman, M. A. CrystalExplorer: A Program for Hirshfeld Surface Analysis, Visualization and Quantitative Analysis of Molecular Crystals. J. Appl. Cryst. 2021, 54 (3), 1006-1011.

(54) Paul, G.; Bisio, C.; Braschi, I.; Cossi, M.; Gatti, G.; Gianotti, E.; Marchese, L. Combined Solid-State NMR, FT-IR and Computational Studies on Layered and Porous Materials. Chem. Soc. Rev. 2018, 47 (15), 5684-5739.

(55) Ma, Y.; Li, N.; Xiang, S.; Guan, N. IR and Raman Investigation of One-Dimensional and Three-Dimensional Aluminophosphite. J. Phys. Chem. C 2007, 111 (49), 18361-18366. 
(56) Takaba, K.; Maki-Yonekura, S.; Inoue, I.; Tono, K.; Hamaguchi, T.; Kawakami, K.; Naitow, H.; Ishikawa, T.; Yabashi, M.; Yonekura, K. Hydrogen Properties in an Organic Molecule Revealed by XFEL and Electron Crystallography. 2021. https://doi.org/10.26434/chemrxiv-2021-jvbfl.

(57) Sobczyk, L.; Grabowski, S. J.; Krygowski, T. M. Interrelation between H-Bond and Pi-Electron Delocalization. Chem. Rev. 2005, 105 (10), 3513-3560.

(58) Gamoke, B.; Neff, D.; Simons, J. Nature of PO Bonds in Phosphates. J. Phys. Chem. A 2009, 113 (19), 56775684.

(59) Pandey, S. K.; Manogaran, D.; Manogaran, S.; Schaefer, H. F. Quantification of Hydrogen Bond Strength Based on Interaction Coordinates: A New Approach. J. Phys. Chem. A 2017, 121 (32), 6090-6103.

(60) Hobza, P. Calculations on Noncovalent Interactions and Databases of Benchmark Interaction Energies. Acc. Chem. Res. 2012, 45 (4), 663-672.

(61) Li, N.; Xiang, S. Hydrothermal Synthesis and Crystal Structure of Two Novel Aluminophosphites Containing Infinite Al-O-Al Chains. J. Mater. Chem. 2002, 12 (5), 1397-1400.

(62) Harvey, H. G.; Teat, S. J.; Tang, C. C.; Cranswick, L. M.; Attfield, M. P. Synthesis and Characterization of Three Novel Cation-Containing $\left(\mathrm{NH}_{4}{ }^{+} / \mathrm{C}_{3} \mathrm{H}_{7} \mathrm{NH}_{3}{ }^{+} / \mathrm{NH}_{3}{ }^{+} \mathrm{C}_{2} \mathrm{H}_{4} \mathrm{NH}_{3}{ }^{+}\right)$Aluminum Diphosphonates. Inorg. Chem. 2003, 42 (7), 2428-2439.

(18)

(1)

(1)

(1)


TOC

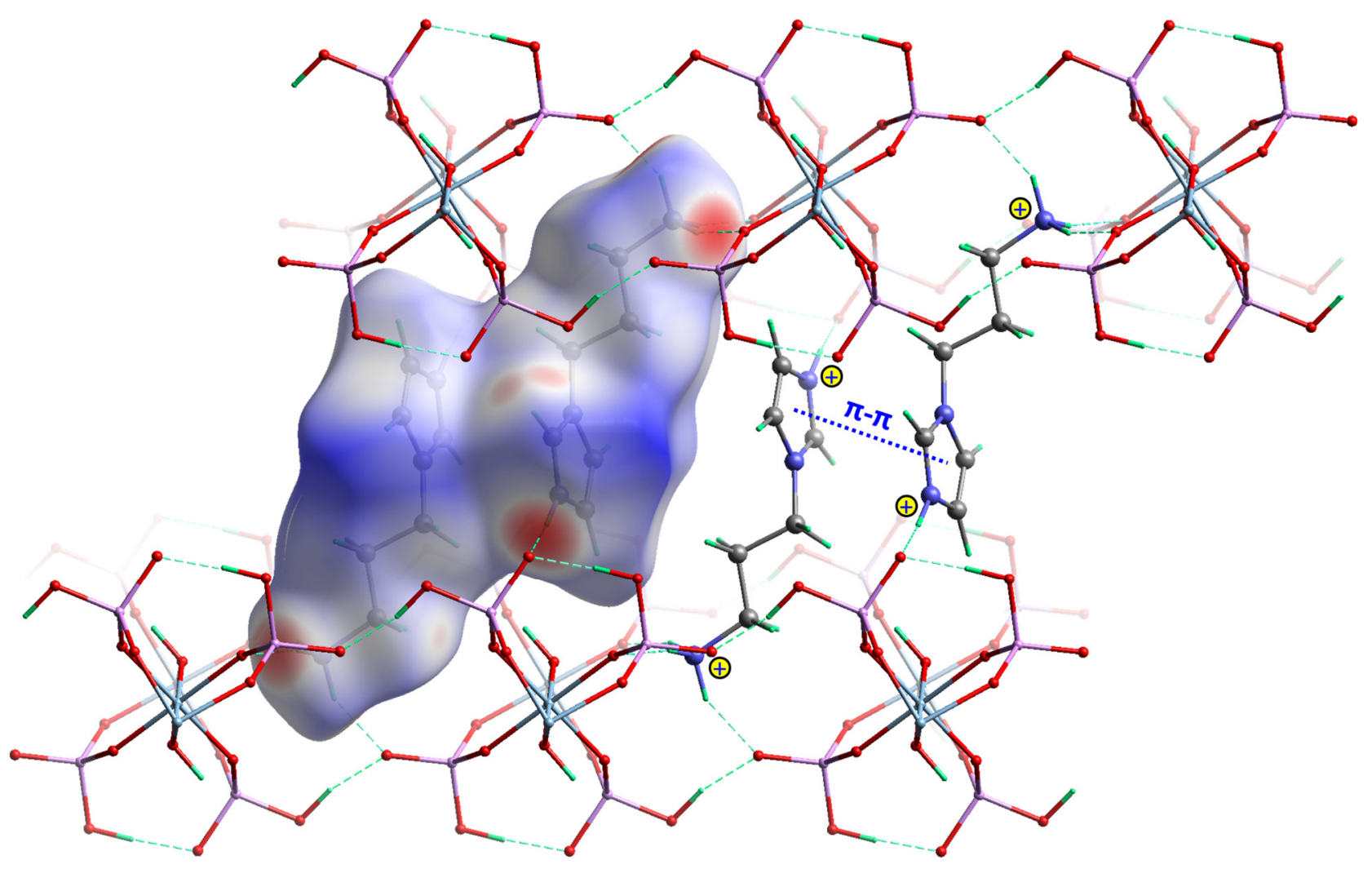

